\title{
2021 revised algorithm for the management of knee osteoarthritis—the Chinese viewpoint
}

\author{
Zhiyi Zhang ${ }^{1} \cdot$ Cibo Huang ${ }^{2} \cdot$ Yongping $\mathrm{CaO}^{3} \cdot{\mathrm{Rong} \mathrm{Mu}^{3} \cdot \text { Mun Chan Zhang }}^{2} \cdot$ Dan Xing $^{4} \cdot$ Dongwei Fan $^{5}$.

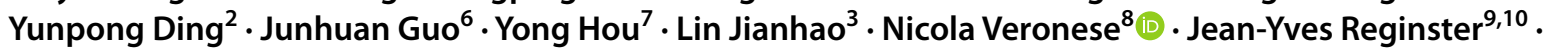 \\ Olivier Bruyere $^{9,10} \cdot$ Etienne Cavalier $^{11} \cdot$ Huaihuan Zhang ${ }^{12}$
}

Received: 14 May 2021 / Accepted: 1 June 2021 / Published online: 29 June 2021

(c) The Author(s) 2021

\begin{abstract}
Aim The European Society for Clinical and Economic Aspects of Osteoporosis, Osteoarthritis and Musculoskeletal Diseases (ESCEO) algorithm for the management of knee osteoarthritis (OA) is available worldwide from 2014, but in 2019 an update was published. Based on this algorithm, a Working Group (WG), including ESCEO members and Chinese experts, wished to see how the new ESCEO algorithm was perceived by Chinese experts in knee OA and how it was integrated into their clinical practice.

Methods A WG was held between members of the international ESCEO task force and a group of Chinese experts.

Results Non-pharmacological approach should be combined with pharmacological interventions. In step 1, symptomatic slow-acting drugs for osteoarthritis (SYSADOA) are the most important background drugs. Evidence, supported by highquality research, is available only for crystalline glucosamine sulfate (pCGS) and chondroitin sulfate. Topical NSAIDs could be used as an additional option. In step 2, oral NSAIDs could be useful, but cardiovascular/renal/gastrointestinal profiles of the patients should be considered. Intra-articular hyaluronic acid and corticosteroids are alternative to oral NSAIDs, but the evidence is still limited. If steps 1 and 2 are not sufficient, weak opioids could be used. Overall, the conclusions of the ESCEO algorithm are accepted in China for products available in this country. The WG suggests the importance of economic studies, specifically made in China.
\end{abstract}

Conclusion This work provides evidence-based advice to establish a treatment algorithm in knee OA, for practical implementation in clinical practice in China.

Keywords Knee osteoartrhitis $\cdot$ Patented crystalline glucosamine sulfate $\cdot$ Symptomatic slow-acting drugs for osteoarthritis · Algorithm $\cdot$ China

Nicola Veronese

nicola.veronese@unipa.it

1 Department of Rheumatology, The First Affiliated Hospital of Harbin Medical University, Harbin, China

2 Department of Rheumatology, Beijing Hospital, Beijing, China

3 Department of Orthopedics, Peking University First Hospital, Beijing, People's Republic of China

4 Arthritis Clinic and Research Center, Peking University People's Hospital, Peking University, Beijing 100044, China

5 Department of Orthopedics, Peking University Third Hospital, Beijing, China

6 Department of Orthopedics, The Affiliated Hospital of Academy of Military Medical Sciences, PLA 307Th Hospital, Beijing 100071, China
7 Department of Rheumatology and Clinical Immunology, Peking Union Medical College Hospital, Chinese Academy of Medical Sciences, Peking Union Medical College, National Clinical Research Center for Dermatologic and Immunologic Diseases, Beijing 100730, China

8 Department of Internal Medicine and Geriatrics, Geriatric Unit, University of Palermo, Palermo, Italy

9 WHO Collaborating Centre for Public Health Aspects of Musculoskeletal Health and Aging, Liège, Belgium

10 Department of Public Health, Epidemiology and Health Economics, University of Liège, CHU Sart Tilman B23, 4000 Liège, Belgium

11 Department of Clinical Chemistry, University of Liège, CHU de Liège, 4000 Liège, Belgium

12 Department of Science and Technology, China Electric Power Research Institute, Beijing, China 


\section{Introduction}

Osteoarthritis (OA) is common, being characterized by typical signs with relevant consequences on functional decline, finally resulting in a relevant loss in quality of life $[1,2]$. Knee is the most common localization of the knee [3]. Symptomatic forms seem to affect more than 250 million people worldwide [3]. Knee OA is estimated among the most common causes of global disability in terms of Disability-Adjusted Life Years (DALY) [4-6].

The European Society for Clinical and Economic Aspects of Osteoporosis, Osteoarthritis and Musculoskeletal Diseases (ESCEO) published some indications for the management of knee OA in 2014, creating a treatment algorithm that gives practical guidance for interventions and therefore guiding physicians through steps based on the severity of knee OA [7]. Since the publication of the 2014 algorithm, new papers are available. In particular, the safety of the medications used for knee $\mathrm{OA}$ is increasing in importance [8-12].

In 2019, a new ESCEO algorithm [13] was published taking into account the recent research on efficacy and safety of medications commonly used for knee OA and the GRADE (Grading of Recommendations Assessment, Development and Evaluation) evaluation was added, to better highlight the evidence used in the algorithm [14]. In these last five years, the ESCEO algorithm has been diffused worldwide and endorsed by many national societies including China, Russia and Southeast Asia [15-19]. Recently, Southeast Asian and European ESCEO experts have produced a new guidance providing evidence-based and easy-to-follow advices on how to establish a treatment algorithm in knee OA, for practical implementation in clinical practice in Southeast countries [20].

Given this background, a working group (WG) was formed including members of the international ESCEO task force (N.V., O.B. E.C., and J.-Y.R.) and a group of Chinese experts in knee OA (working group, WG) to see how key opinion leaders in China perceive ESCEO algorithm and how it can be combined, with their own clinical daily practice, for harmonizing and optimizing the management of their patients affected by knee OA.

\section{Epidemiological data of knee osteoarthritis in China}

The interest of Chinese public health authorities and physicians in knee OA is exponentially increasing as well as the epidemiological interest in the potential risk factors for knee OA. Knee OA is a very common condition in China, with about $8 \%$ of people with a symptomatic form [21] and with a prevalence of mild, moderate and severe knee OA of $1.5 \%$, $3.3 \%$, and $3.9 \%$, respectively [22]. The risk factors for knee OA have a critical importance in research regarding knee OA epidemiology. Among them, obesity seems to be one of the most important [23]. Some recent data, specific for the Chinese population, indicated that the actual prevalence of obesity in this country is continuously increasing: obesity in China is a major health concern according to the World Health Organization, with a prevalence of about $5 \%$, but greater than $20 \%$ in some cities where fast food is popular [24]. Obesity is strongly associated with the presence of knee OA, as a large meta-analysis reported [25]. Another factor that seems to be important in Chinese vision of knee $\mathrm{OA}$ is the presence of abnormal joints at birth (i.e. congenital abnormalities) and genetic factors [26]. These people, in fact, were born with abnormally formed joints, vulnerable to mechanical wear, causing early degeneration and loss of joint cartilage. Moreover, some genetic factors, specific for Chinese people, seem to be associated with an increased risk of knee OA [27]. Finally, another important risk factor in China for knee OA is the prevalence of metabolic abnormalities, in particular, type 2 diabetes mellitus [28, 29].

\section{Non-pharmacological treatment in the 2019 ESCEO algorithm}

Non-pharmacological interventions (information/education; weight loss in case of overweight or obesity; physical exercise mixing aerobic and strengthening exercises) have a relevant role being supported by a high level of evidence according to the GRADE $[7,13,30]$. However, it is widely accepted that the real effect of these interventions is limited and their feasibility in the long term is still unclear [31]. In China, the core interventions, including exercise, education, and weight loss, are widely used. Furthermore, the Chinese experts, during the workshop, highlighted the importance of Tai-Chi [32, 33] and acupuncture [34, 35], typical Chinese traditions, for their patients.

\section{Pharmacological treatment in the 2019 ESCEO algorithm}

\section{Step 1: background treatment}

\section{Paracetamol}

Paracetamol (acetaminophen) is among the most used medication in the world, including the treatment of knee OA symptoms. In 2014 ESCEO reported that paracetamol has only a marginal effect on pain without any significant 
effect on stiffness or physical function in knee OA [36-38]. In the last years, several concerns are rising regarding the safety of paracetamol, due to the increasing research reporting that the risk of gastrointestinal (GI), cardiovascular (CV), hepatic and renal adverse events (AEs) [39] and finally mortality [40] should be deeply considered. Based on this evidence (robust evidence of AEs and limited effect), the 2019 ESCEO algorithm recommends that paracetamol should be used only as rescue medication, in case of the inefficacy of the background therapy [13]. Moreover, as observed by the Chinese experts of the WG, paracetamol is not widely used in China and, when used in more severe forms of knee OA.

\section{SYSADOAs}

In 2014 and 2019 versions of the ESCEO algorithm, Step 1 treatment recommends to start background therapy with long-term SYSADOAs (Symptomatic Slow-acting Drugs for Osteoarthritis) [7, 13]. However, this class includes several products such as glucosamine, chondroitin, diacerein, and avocado soybean unsaponifiables (ASU), which are supported by varying degrees of clinical efficacy and safety data.

Glucosamine and chondroitin are natural compounds. Glucosamine hydrochloride $(\mathrm{GHCl})$ is obtained using an extraction process and often used as a nutraceutical or overthe-counter (OTC) products. Conversely, glucosamine sulfate (GS) is a more complex product, obtained only by a proprietary semi-synthetic route and stabilization process. This important process is used only in the prescription-grade crystalline glucosamine sulfate (pCGS) [41]. Finally, some recent observational findings in the UK Biobank suggest that GS can be useful in decreasing cardiovascular risk [42]. Unfortunately, multiple formulations of GS are available [43], both as prescription-grade products and OTC, but the latter products usually have limited amounts of glucosamine. On the contrary, only pCGS is able to deliver in an appropriate way a clinical efficacious glucosamine bioavailability and plasma concentration, resulting in good clinical efficacy [44-51]. On the contrary, $\mathrm{GHCl}$ and non-crystalline glucosamine sulfate products (usually consisting of $\mathrm{GHCl}$ with the addition of sodium sulfate to get a "sulfate" labelling) are ineffective in the treatment of knee OA [44, 46, 52-56]. A similar evidence can be applied to chondroitin sulfate [57-63], even if this product in the world (including China) is less commercially diffused. Based on the scientific evidence available, ESCEO specifically recommends the use of pCGS and long-acting chondroitin sulfate products (the latter of which are not available in China) in both versions of the algorithm published in 2014 and 2019 [7, 13].
The judgement regarding SYSADOAs is also based on their safety since, except for diacerein, several randomized placebo-controlled trials (RCTs) have demonstrated that SYSADOAs are safe, both considering total and specific events [11]. When discussing of pCGS and CS, we have a robust literature indicating that the use of pCGS is able to reduce by about $50 \%$ the indication for the TKR and the use of medications showed in step 2 in a similar way [64, 65]. Moreover, pCGS has been suggested to be cost-effective since using an analysis including ten different studies, only the use of pCGS is cost-effective, whilst other formulations (crystalline glucosamine sulfate, glucosamine sulfate, and glucosamine hydrochloride) are not [55]. However, since no Chinese work was included, the WG encourages specific research on economic costs in China.

Regarding AEs, hypothetical concerns have been raised regarding the safety of pCGS in patients having diabetes. Glucosamine is an amino sugar that might lead to hyperglycemia and insulin resistance, through the over-activation of the hexosamine pathway [66]. However, it was already known that when in plasma glucosamine "does not go back to glucose", but is directly catabolized without any interference with glucose metabolism [67]. This statement is supported by the clinical trials' data in human beings. At common doses used for OA treatment, pCGS showed no interference with glucose metabolism in subjects with normal plasma glucose levels and in most subjects with hyperglycemia, impaired insulin sensitivity, pre-diabetes or diabetes [52, 68]. In addition, a meta-analysis on the effects of glucosamine on glucose metabolism found that glucosamine, at the usual oral doses used in knee OA patients, is well-tolerated by normal, diabetic, or pre-diabetic patients [69]. In the PROOF trial a non-significant increase in glycated hemoglobin levels was found in overweight women who received pCGS during the follow-up period [70, 71]. Therefore, the WG recommends to advise caution at the start of treatment with glucosamine in diabetic patients [28].

\section{Topical NSAIDs}

In the background therapy of knee OA, topical non-steroidal anti-inflammatory drugs (NSAIDS) might be used as cyclic therapy if the patient is still symptomatic after treatment with SYSADOAs. Topical NSAIDs are considered safe [8], but their efficacy has been only demonstrated in short-term RCTs. Therefore, more data are needed for confirming their clinical impact [13]. The 2019 algorithm suggested that topical NSAIDs might be used in preference to oral NSAIDs, particularly in frail patients affected by knee OA, or prior to use of oral NSAIDs. The Chinese WG agreed with the use of topical NSAIDs for the control of persistent pain in knee OA. 


\section{Step 2: advanced pharmacological treatment}

Step 2 includes patients still suffering after the background therapy or with relevant limitations in the activities of daily living. In the second step, a relevant role is covered by oral NSAIDs. Based on the literature available with a particular attention to the safety of these medications [10], ESCEO makes a strong recommendation to the use of oral NSAIDs (selective or non-selective), but only intermittently and for a short period [13]. Furthermore, ESCEO underlines that the use of oral NSAIDs should be based on the patient risk profile, with a particular attention for cardiovascular, renal, and gastrointestinal profile [13]. Regarding the safety of oral NSAIDs, it is important to remember that, after removing rofecoxib, the cardiovascular risk decreased.

In the second part of step 2, intra-articular medications (hyaluronic acid and corticosteroids) are indicated. However, for both these intra-articular products, there is a weak evidence supporting the use of intra-articular medications in those who cannot take oral NSAIDs (e.g., allergy). A recent RCT, for example, found that physical therapy is better than corticosteroids injection for improving disability and pain in people with knee OA [72]. The reasons for this decision regarding intra-articular drugs are based on their efficacy, higher risk of AEs when compared to placebo and only having short-term RCTs supporting the use of these drugs [9, 13].

In conclusion, in step 2, the WG agreed to the judicious use of NSAIDs for acute exacerbation of knee OA, particularly in the case of an inflammatory component, after carefully considering the patient profile. The dose of NSAIDs should be the lowest effective dose.

\section{Step 3: last pharmacological treatment}

Last pharmacological options for the still symptomatic patients are represented by short-term weak opioids. Tramadol may give benefits on analgesia in knee OA [73, 74], but a recent meta-analysis of the safety of oral opioids used in OA found an increased risk of gastrointestinal, central nervous system, and dermatological AEs when tramadol is compared with placebo [75]. For this reason, ESCEO gives only a weak recommendation to the use of short-term weak opioids, as the last pharmacological option before surgery [13]. A similar evidence base is available for duloxetine, for which a very limited efficacy is observed [13].

The WG concurs to the use of low-dose weak opioids, like tramadol, with the needed precaution for their known adverse events of nausea, somnolence, and vomiting.

\section{Step 4: end-stage disease management and surgery}

Total knee replacement (TKR) is appropriate when all previous interventions have failed, in case of the patient still symptomatic, and when a significant loss in quality of life is present [76-78]. However, for patients in whom surgery is cotraindicated, the last pharmacological attempt could be oral or transdermal opioids [79], which should be prescribed following the guidelines for use of opioid analgesics in the management of non-cancer pain [80].

The WG adds that background physical therapy is to be continued for surgery-averse patients or those where surgery is contraindicated.

\section{Conclusions}

Knee OA is a relevant problem in China, exponentially increasing, also for the rise of the risk factors associated with this condition, such as obesity. In this work, the WG has tried to summarize the reccomendations given in the 2019 ESCEO algorithm, highlighting specific areas where it applies to clinical practice Chinese people. In China, the steps of the 2019 algorithm are not only followed but also recognized as important. Our work further provides evidence-based and easy-to-follow advices regarding to establish a treatment algorithm in patients with knee OA, for practical implementations in the Chinese clinical practice.

Funding Open access funding provided by Università degli Studi di Palermo within the CRUI-CARE Agreement.

\section{Declarations}

Conflict of interest JYR reports consulting fees or paid advisory boards from Ibsa-Genevrier, Mylan, Radius Health, Pierre Fabre; lecture fees when speaking at the invitation of sponsor: Ibsa-Genevrier, Mylan, Cniel, Dairy Research Council (Drc); Grant Support from Industry (All through Institution): Ibsa-Genevrier, Mylan, Cniel, Radius Health; NV has participated in Advisory Boards for Mylan, Fidia, Sanofi-Aventis; OB reports grants/fees from Amgen, Aptissen, Biophytis, IBSA, MEDA, Novartis, Servier, SMB, and Theramex. The other authors did not declare any conflict of interest.

Ethics approval This research used already published material. The Ethics approval was not requested.

Open Access This article is licensed under a Creative Commons Attribution 4.0 International License, which permits use, sharing, adaptation, distribution and reproduction in any medium or format, as long as you give appropriate credit to the original author(s) and the source, provide a link to the Creative Commons licence, and indicate if changes were made. The images or other third party material in this article are included in the article's Creative Commons licence, unless indicated otherwise in a credit line to the material. If material is not included in 
the article's Creative Commons licence and your intended use is not permitted by statutory regulation or exceeds the permitted use, you will need to obtain permission directly from the copyright holder. To view a copy of this licence, visit http://creativecommons.org/licenses/by/4.0/.

\section{References}

1. Murray CJ, Vos T, Lozano R et al (2012) Disability-adjusted life years (DALYs) for 291 diseases and injuries in 21 regions, 1990-2010: a systematic analysis for the Global Burden of Disease Study 2010. Lancet 380:2197-2223

2. Woolf AD, Pfleger B (2003) Burden of major musculoskeletal conditions. Bull World Health Organ 81:646-656

3. Vos T, Flaxman AD, Naghavi M et al (2012) Years lived with disability (YLDs) for 1160 sequelae of 289 diseases and injuries 1990-2010: a systematic analysis for the Global Burden of Disease Study 2010. Lancet 380:2163-2196

4. Cross M, Smith E, Hoy D et al (2014) The global burden of hip and knee osteoarthritis: estimates from the global burden of disease 2010 study. Ann Rheum Dis 73:1323-1330

5. Clynes MA, Jameson KA, Edwards MH et al (2019) Impact of osteoarthritis on activities of daily living: does joint site matter? Aging Clin Exp Res 31:1049-1056

6. Beaudart $\mathrm{C}$, Biver $\mathrm{E}$, Bruyère $\mathrm{O}$ et al (2018) Quality of life assessment in musculo-skeletal health. Aging Clin Exp Res 30:413-418

7. Bruyere O, Cooper C, Pelletier JP et al (2014) An algorithm recommendation for the management of knee osteoarthritis in Europe and internationally: a report from a task force of the European Society for Clinical and Economic Aspects of Osteoporosis and Osteoarthritis (ESCEO). Semin Arthritis Rheum 44:253-263

8. Honvo G, Leclercq V, Geerinck A et al (2019) Safety of topical non-steroidal anti-inflammatory drugs in osteoarthritis: outcomes of a systematic review and meta-analysis. Drugs Aging 36:45-64

9. Honvo G, Reginster J-Y, Rannou F et al (2019) Safety of intraarticular hyaluronic acid injections in osteoarthritis: outcomes of a systematic review and meta-analysis. Drugs Aging 36:101-127

10. Cooper C, Chapurlat R, Al-Daghri N et al (2019) Safety of oral non-selective non-steroidal anti-inflammatory drugs in osteoarthritis: what does the literature say? Drugs Aging 36:15-24

11. Honvo G, Reginster J-Y, Rabenda V et al (2019) Safety of symptomatic slow-acting drugs for osteoarthritis: outcomes of a systematic review and meta-analysis. Drugs Aging 36:65-99

12. Bruyere O, Cooper C, Pelletier J-P et al (2016) A consensus statement on the European Society for Clinical and Economic Aspects of Osteoporosis and Osteoarthritis (ESCEO) algorithm for the management of knee osteoarthritis-from evidence-based medicine to the real-life setting. Semin Arthritis Rheum 45:S3-S11

13. Bruyère $\mathrm{O}$, Honvo $\mathrm{G}$, Veronese $\mathrm{N}$ et al (2019) An updated algorithm recommendation for the management of knee osteoarthritis from the European Society for Clinical and Economic Aspects of Osteoporosis, Osteoarthritis and Musculoskeletal Diseases (ESCEO). Semin Arthritis Rheum 49:337-350

14. Guyatt GH, Oxman AD, Vist GE et al (2008) GRADE: an emerging consensus on rating quality of evidence and strength of recommendations. BMJ 336:924

15. Zhang Z, Duan X, Gu J et al (2016) The European Society for Clinical and Economic Aspects of Osteoporosis and Osteoarthritis (ESCEO) algorithm for the management of knee osteoarthritis is applicable to Chinese clinical practice: a consensus statement of leading Chinese and ESCEO osteoarthritis experts. Chin J Pract Int Med 36:762-772

16. Denisov L, Tsvetkova E, Golubev G et al (2016) The European Society for Clinical and Economic Aspects of Osteoporosis and Osteoarthritis (ESCEO) algorithm for the management of knee osteoarthritis is applicable to Russian clinical practice: a consensus statement of leading Russian and ESCEO osteoarthritis experts. Научно-практическая ревматология/Rheumatol Sci Pract 54:641-652

17. Saengnipanthkul S, Waikakul S, Rojanasthien S et al (2019) Differentiation of patented crystalline glucosamine sulfate from other glucosamine preparations will optimize osteoarthritis treatment. Int J Rheum Dis 22:376-385

18. Bruyere O, Cooper C, Cutolo M et al (2017) International endorsement of the ESCEO algorithm for management of knee osteoarthritis in clinical practice. Semin Arthritis Rheum 47:e10

19. Xia W, Cooper C, Li M et al (2019) East meets West: current practices and policies in the management of musculoskeletal aging. Aging Clin Exp Res 31:1351-1373

20. Yeap SS, Tanavalee A, Perez EC et al (2021) 2019 revised algorithm for the management of knee osteoarthritis: the Southeast Asian viewpoint. Aging Clin Exp Res 33:1149-1156

21. Tang X, Wang S, Zhan S et al (2016) The prevalence of symptomatic knee osteoarthritis in China: results from the China health and retirement longitudinal study. Arthritis Rheumatol 68:648-653

22. Liu Q, Wang S, Lin J et al (2018) The burden for knee osteoarthritis among Chinese elderly: estimates from a nationally representative study. Osteoarthr Cartil 26:1636-1642

23. Yu S, Guo X, Yang H et al (2020) Cardiometabolic comorbidities and epidemiological features among rural Chinese elderly people. Aging Clin Exp Res 32:1-12

24. Liu X, Wu W, Mao Z et al (2018) Prevalence and influencing factors of overweight and obesity in a Chinese rural population: the Henan Rural Cohort Study. Sci Rep 8:1-11

25. Zheng H, Chen $\mathrm{C}$ (2015) Body mass index and risk of knee osteoarthritis: systematic review and meta-analysis of prospective studies. BMJ Open 5:e007568

26. Dequeker J, Aerssens J, Luyten FP (2003) Osteoarthritis and osteoporosis: clinical and research evidence of inverse relationship. Aging Clin Exp Res 15:426-439

27. Wang L, Guo L, Tian F et al (2015) Analysis of single nucleotide polymorphisms within ADAM12 and risk of knee osteoarthritis in a Chinese Han population. BioMed Res Int 2015:518643

28. Veronese N, Cooper C, Reginster J-Y et al (2019) Type 2 diabetes mellitus and osteoarthritis. Semin Arthritis Rheum 49:9-19

29. Zhang Q, Wang Y, Yu N et al (2021) Metabolic syndrome predicts incident disability and functional decline among Chinese older adults: results from the China Health and Retirement Longitudinal Study. Aging Clin Exp Res. https://doi.org/10.1007/ s40520-021-01827-w

30. Fernandes L, Hagen KB, Bijlsma JW et al (2013) EULAR recommendations for the non-pharmacological core management of hip and knee osteoarthritis. Ann Rheum Dis 72:1125-1135

31. Cutolo M, Berenbaum F, Hochberg M et al (2014) Commentary on recent therapeutic guidelines for osteoarthritis. Semin Arthritis Rheum 44:611-617

32. Lauche R, Langhorst J, Dobos G et al (2013) A systematic review and meta-analysis of Tai Chi for osteoarthritis of the knee. Complement Ther Med 21:396-406

33. Wang S, Yin H, Wang X et al (2019) Efficacy of different types of exercises on global cognition in adults with mild cognitive impairment: a network meta-analysis. Aging Clin Exp Res 31:1391-1400

34. Zhang Q, Yue J, Golianu B et al (2017) Updated systematic review and meta-analysis of acupuncture for chronic knee pain. Acupunct Med 35:392-403

35. Pan X, Meng H (2020) Pain management and cognitive function among older adults: an exploratory study of the China Health and Retirement Longitudinal Study. Aging Clin Exp Res 32:2611-2620 
36. Towheed TE, Maxwell L, Judd MG et al (2006) Acetaminophen for osteoarthritis. Cochrane Database Syst Rev CD004257

37. Zhang W, Nuki G, Moskowitz RW et al (2010) OARSI recommendations for the management of hip and knee osteoarthritis: part III: changes in evidence following systematic cumulative update of research published through January 2009. Osteoarthr Cartil 18:476-499

38. Bannuru RR, Schmid CH, Kent DM et al (2015) Comparative effectiveness of pharmacologic interventions for knee osteoarthritis: a systematic review and network meta-analysis. Ann Intern Med 162:46-54

39. Conaghan PG, Arden N, Avouac B et al (2019) Safety of paracetamol in osteoarthritis: what does the literature say? Drugs Aging 36:7-14

40. Lipworth L, Friis S, Mellemkjaer L et al (2003) A populationbased cohort study of mortality among adults prescribed paracetamol in Denmark. J Clin Epidemiol 56:796-801

41. De Wan M, Volpi G (1998) Method of preparing mixed glucosamine salts. Google Patents

42. Ma H, Li X, Sun D et al (2019) Association of habitual glucosamine use with risk of cardiovascular disease: prospective study in UK Biobank. BMJ 365:1628

43. Bruyère $\mathrm{O}$, Cooper $\mathrm{C}, \mathrm{Al}$-Daghri $\mathrm{NM}$ et al (2018) Inappropriate claims from non-equivalent medications in osteoarthritis: a position paper endorsed by the European Society for Clinical and Economic Aspects of Osteoporosis, Osteoarthritis and Musculoskeletal Diseases (ESCEO). Aging Clin Exp Res 30:111-117

44. Towheed TE, Maxwell L, Anastassiades TP et al (2009) Glucosamine therapy for treating osteoarthritis. Cochrane Database Syst Rev CD002946

45. Reginster JY (2007) The efficacy of glucosamine sulfate in osteoarthritis: financial and nonfinancial conflict of interest. Arthritis Rheum 56:2105-2110

46. Eriksen P, Bartels EM, Altman RD et al (2014) Risk of bias and brand explain the observed inconsistency in trials on glucosamine for symptomatic relief of osteoarthritis: a meta-analysis of placebo-controlled trials. Arthritis Care Res (Hoboken) 66:1844-1855

47. Reginster JY, Deroisy R, Rovati LC et al (2001) Long-term effects of glucosamine sulphate on osteoarthritis progression: a randomised, placebo-controlled clinical trial. Lancet 357:251-256

48. Pavelka K, Gatterova J, Olejarova M et al (2002) Glucosamine sulfate use and delay of progression of knee osteoarthritis: a 3-year, randomized, placebo-controlled, double-blind study. Arch Intern Med 162:2113-2123

49. Herrero-Beaumont G, Ivorra JA, Del Carmen TM et al (2007) Glucosamine sulfate in the treatment of knee osteoarthritis symptoms: a randomized, double-blind, placebo-controlled study using acetaminophen as a side comparator. Arthritis Rheum 56:555-567

50. Bruyere O, Altman RD, Reginster J-Y (2016) Efficacy and safety of glucosamine sulfate in the management of osteoarthritis: evidence from real-life setting trials and surveys. Semin Arthritis Rheum 45:S12-S17

51. Kucharz EJ, Kovalenko V, Szanto S et al (2016) A review of glucosamine for knee osteoarthritis: why patented crystalline glucosamine sulfate should be differentiated from other glucosamines to maximize clinical outcomes. Curr Med Res Opin 32:997-1004

52. Clegg DO, Reda DJ, Harris CL et al (2006) Glucosamine, chondroitin sulfate, and the two in combination for painful knee osteoarthritis. N Engl J Med 354:795-808

53. Runhaar J, Rozendaal RM, Middelkoop MV et al (2017) Subgroup analyses of the effectiveness of oral glucosamine for knee and hip osteoarthritis: a systematic review and individual patient data meta-analysis from the OA trial bank. Ann Rheum Dis 76:1862-1869
54. Reginster JL, Bruyere O, Cooper C (2017) Different glucosamine sulfate products generate different outcomes on osteoarthritis symptoms. Ann Rheum Dis 77:e39

55. Bruyère O, Reginster J-Y, Honvo G et al (2019) Cost-effectiveness evaluation of glucosamine for osteoarthritis based on simulation of individual patient data obtained from aggregated data in published studies. Aging Clin Exp Res 31:881-887

56. Veronese N, Demurtas J, Smith L et al (2020) Glucosamine sulphate: an umbrella review of health outcomes. Therap Adv Musculoskel Dis 12:1759720X20975927

57. Volpi N (2009) Quality of different chondroitin sulfate preparations in relation to their therapeutic activity. J Pharm Pharmacol 61:1271-1280

58. Kahan A, Uebelhart D, De Vathaire F et al (2009) Long-term effects of chondroitins 4 and 6 sulfate on knee osteoarthritis: the study on osteoarthritis progression prevention, a two-year, randomized, double-blind, placebo-controlled trial. Arthritis Rheum 60:524-533

59. Zegels B, Crozes P, Uebelhart D et al (2013) Equivalence of a single dose $(1200 \mathrm{mg})$ compared to a three-time a day dose (400 $\mathrm{mg}$ ) of chondroitin $4 \& 6$ sulfate in patients with knee osteoarthritis. Results of a randomized double blind placebo controlled study. Osteoarthr Cartil 21:22-27

60. Schneider H, Maheu E, Cucherat M (2012) Symptom-modifying effect of chondroitin sulfate in knee osteoarthritis: a metaanalysis of randomized placebo-controlled trials performed with structum((R)). Open Rheumatol J 6:183-189

61. Reginster JY, Dudler J, Blicharski T et al (2017) Pharmaceuticalgrade Chondroitin sulfate is as effective as celecoxib and superior to placebo in symptomatic knee osteoarthritis: the ChONdroitin versus CElecoxib versus Placebo Trial (CONCEPT). Ann Rheum Dis 76:1537-1543

62. Honvo G, Bruyère O, Reginster J-Y (2019) Update on the role of pharmaceutical-grade chondroitin sulfate in the symptomatic management of knee osteoarthritis. Aging Clin Exp Res 31:1163-1167

63. Reginster J-Y, Veronese N (2020) Highly purified chondroitin sulfate: a literature review on clinical efficacy and pharmacoeconomic aspects in osteoarthritis treatment. Aging Clin Exp Res 33:37-47

64. Rovati LC, Girolami F, D’Amato M et al (2016) Effects of glucosamine sulfate on the use of rescue non-steroidal anti-inflammatory drugs in knee osteoarthritis: results from the Pharmaco-Epidemiology of GonArthroSis (PEGASus) study. Semin Arthritis Rheum 45:S34-S41

65. Bruyère O, Pavelka K, Rovati L et al (2008) Total joint replacement after glucosamine sulphate treatment in knee osteoarthritis: results of a mean 8-year observation of patients from two previous 3-year, randomised, placebo-controlled trials. Osteoarthr Cartil $16: 254-260$

66. Rossetti L, Hawkins M, Chen W et al (1995) In vivo glucosamine infusion induces insulin resistance in normoglycemic but not in hyperglycemic conscious rats. J Clin Investig 96:132-140

67. Neil KM, Caron JP, Orth MW (2005) The role of glucosamine and chondroitin sulfate in treatment for and prevention of osteoarthritis in animals. J Am Vet Med Assoc 226:1079-1088

68. Muniyappa R, Karne RJ, Hall G et al (2006) Oral glucosamine for 6 weeks at standard doses does not cause or worsen insulin resistance or endothelial dysfunction in lean or obese subjects. Diabetes 55:3142-3150

69. Dostrovsky N, Towheed T, Hudson R et al (2011) The effect of glucosamine on glucose metabolism in humans: a systematic review of the literature. Osteoarthr Cartil 19:375-380

70. Runhaar J, Deroisy R, van Middelkoop M et al (2016) The role of diet and exercise and of glucosamine sulfate in the prevention of knee osteoarthritis: further results from the PRevention of knee 
Osteoarthritis in Overweight Females (PROOF) study. Semin Arthritis Rheum 45:S42-S48

71. Gommans YM, Runhaar J, Jacobs ML et al (2017) The effect of prolonged glucosamine usage on HbA1c Levels and new-onset diabetes mellitus in overweight and obese middle-aged women. Am J Med 130:731-737

72. Deyle GD, Allen CS, Allison SC et al (2020) Physical therapy versus glucocorticoid injection for osteoarthritis of the knee. $\mathrm{N}$ Engl J Med 382:1420-1429

73. Cepeda MS, Camargo F, Zea C et al (2006) Tramadol for osteoarthritis. Cochrane Database Syst Rev CD005522

74. Pelletier JP, Martel-Pelletier J, Rannou F et al (2016) Efficacy and safety of oral NSAIDs and analgesics in the management of osteoarthritis: evidence from real-life setting trials and surveys. Semin Arthritis Rheum 45:S22-S27

75. Fuggle N, Curtis E, Shaw S et al (2019) Safety of opioids in osteoarthritis: outcomes of a systematic review and meta-analysis. Drugs Aging 36:129-143

76. Bruyere O, Ethgen O, Neuprez A et al (2012) Health-related quality of life after total knee or hip replacement for osteoarthritis: a 7-year prospective study. Arch Orthop Trauma Surg 132:1583-1587
77. Ethgen O, Bruyere O, Richy F et al (2004) Health-related quality of life in total hip and total knee arthroplasty. A qualitative and systematic review of the literature. J Bone Joint Surg Am 86:963-974

78. Shan L, Shan B, Suzuki A et al (2015) Intermediate and long-term quality of life after total knee replacement: a systematic review and meta-analysis. J Bone Joint Surg Am 97:156-168

79. Nuesch E, Rutjes AW, Husni E et al (2009) Oral or transdermal opioids for osteoarthritis of the knee or hip. Cochrane Database Syst Rev CD003115

80. Manchikanti L, Kaye AM, Knezevic NN et al (2017) Responsible, safe, and effective prescription of opioids for chronic non-cancer pain: American Society of Interventional Pain Physicians (ASIPP) Guidelines. Pain Phys 20:S3-S92

Publisher's Note Springer Nature remains neutral with regard to jurisdictional claims in published maps and institutional affiliations. 